\title{
Prescribed burning and its effect on plant biomass and species diversity in savanna ecosystem, Sokoto, Nigeria
}

\author{
M. B. OYUN ${ }^{1 *}$ and A. D. ISAH ${ }^{2}$ \\ ${ }^{1}$ Department of Forestry and Wood Technology, Federal University of Technology, \\ P.M.B.704, Akure, Nigeria. \\ ${ }^{2}$ Department of Forestry and Fisheries, Usmanu Danfodiyo University, Sokoto, Nigeria. \\ *Corresponding author, E-mail: banjioyun@yahoo.com
}

\begin{abstract}
Three burning regime (fire protected, early burning, late burning) and their effects on plant biomass and species diversity in Dabagi forest Reserve of Sokoto State were investigated. Prescribed burning was carried out on randomly selected plots $(10 \mathrm{~m} \times 10 \mathrm{~m}$ ) in November (early burn) and March (late burn) 2004. The design of experiment was a Randomized Complete Block Design (RCBD) and the burning treatments were replicated three times. The data obtained were analyzed using analysis of variance. The diversity index of the shrubs species was higher $(\mathrm{P}<0.05)$ in the early burnt plot $\left(\mathrm{H}^{1}=0.86\right)$ than in the late burnt plot $\left(\mathrm{H}^{1}=0.66\right)$, even though the species richness index in the late burnt plot $(\mathrm{d}=3.31)$ was higher than that of the early burnt plot $(\mathrm{d}=2.50)$. Species evenness index was higher $(\mathrm{P}<0.05)$ in the early burnt plot $(\mathrm{E}=1.00)$ than in the late burnt plot $(\mathrm{E}=0.92)$, indicating that the shrub species in the early burnt plot shows greater uniformity in the distribution of individual among the taxa, hence the higher species diversity. Similarly for forbs and grasses, the diversity index was higher in the early burnt plot $\left(\mathrm{H}^{1}=0.89\right)$ while it was least in the late burnt plot $\left(\mathrm{H}^{1}=0.83\right)$. The grass species biomass $\left(\mathrm{g} / \mathrm{m}^{2}\right)$ production were higher in the early burnt plots than in the late burnt plot during the nine-month post fire sampling period, while late burning initiated higher forbs biomass than the biomass of grasses throughout the nine-month post fire period.

(C) 2009 International Formulae Group. All rights reserved.
\end{abstract}

Key words: Burning regime, evenness, indices, richness and species.

\section{INTRODUCTION}

Fires that burned tens and hundreds of thousand of acres have occurred in several places around the world (e.g., California, Idaho, Montana, Oregon, Washington, Nigeria and Ghana) (Martin and Sapsis, 1992; Agee, 1993; Johnson et al., 1994). While most ecosystems occasionally experience very large fires (Romme and Despain, 1989), the present-day frequency of such large fires appears unprecedented. The savanna ecosystems is structurally homogenous and are conducive to large, severe fires especially during hot, dry, windy periods in late summer or early fall. Ecosystem recovery following standing replacing fires potentially follows four stand-development stages: stand initiation, stem exclusion, under story reinitiation and old growth (Oliver and Larson, 1990).

However, the status of plant species richness, biomass growth and diversity at any stage of fire recovery will depend on the severity of burn and the type of ecosystem (forest or savanna), as ecosystems respond differently to fire suppression (Agee, 1993). Therefore, the aim of the present study is to assess the effects of early and late burning on plant biomass production and evaluate its 
impact on species diversity, richness and evenness in savanna ecosystem.

\section{MATERIALS AND METHODS Study area}

The study was conducted in Dabagi forest reserve located in Dange/Shuni local government area of Sokoto State, Nigeria. It is situated between latitude $11^{\circ} 30$ to $13^{\circ} 50 \mathrm{~N}$ and longitude $4^{\circ}$ to $60^{\circ} \mathrm{E}$ (Federal surveys, 1964). The larger population is settled in Dange and Shuni villages, but smaller settlements are scattered around the reserve. The people are mixture of Hausa/Fulani, with a nomadic way of life. The climate is hot semi-arid type characterized by a long and severe dry season lasting from October until May and short but intensive wet season from May/June until September.

\section{Field experiments}

An area measuring $100 \mathrm{~m} \times 100 \mathrm{~m}$ was demarcated and was thereafter divided into plots of $10 \mathrm{~m}$ x $10 \mathrm{~m}$ separated by $1 \mathrm{~m}$ fire tracks. Three burning treatments (early burning, late burning and fire protected) were randomly distributed to the experimental plots in a randomized complete block design at three replicates per treatment. Early burning was carried out at the beginning of dry season (November/December), while the late burning was conducted at the extreme end of dry season (March/April) when the vegetation was completely dry.

\section{Plant sampling procedure}

The plant population was sampled according to the techniques described by Van Dyke et al. (2004). At each of the sample plots $5 \mathrm{~m} \mathrm{x} 5 \mathrm{~m}$ plots were randomly located for the enumeration of the shrub species. The number of each shrub species were counted, identified and recorded. Furthermore within each sample plots, $1 \mathrm{~m}$ x $1 \mathrm{~m}$ quadrats were randomly located at three replicates for the enumeration of forbs. The forbs population within each quadrat were counted, identified and recorded. Thereafter in each of the $1 \mathrm{~m} \mathrm{x}$ $1 \mathrm{~m}$ quadrat, $30 \mathrm{~cm} \times 30 \mathrm{~cm}$ land area was laid for the enumeration of the grass species (Collins, 2000). This sampling procedure was repeated in the burnt plots after the first notice of regrowth at one-month interval for a period of nine months.

\section{Plant biomass estimation}

All samples of plant were sorted out by species and dried to constant weight in an oven maintained at $75{ }^{\circ} \mathrm{C}$ for $24 \mathrm{~h}$ and weighed. The dried weight of the plant materials were calculated and expressed in $\mathrm{g} / \mathrm{m}^{2}$. The data were used to construct the productivity estimates for the plant species relative to each fire treatment (Brockway and Lewis, 1997).

\section{Estimation of plant diversity, evenness and richness}

The diversity and abundance of plant species in the different treatment plots were compared using indices of diversity. Three ecological indices (diversity, evenness and richness) were estimated for each burning treatment. These include:

Shannon weiner index $\left(\mathrm{H}^{1}\right)$ of diversity which was given as:

$$
\begin{aligned}
& \mathrm{H}^{1}=\frac{\mathrm{N} \log \mathrm{N}-\mathrm{ni} \log ^{\mathrm{k}} \mathrm{ni}}{\mathrm{N}=1} \\
& \text { Where: } \\
& \mathrm{N}=\text { Total No. of individuals } \\
& \text { ni }=\text { No. of individuals in species (I) } \\
& \mathrm{k}=\text { Total No. of species }
\end{aligned}
$$

- Evenness index (E) which expresses the degree of uniformity in the distribution of individuals among the taxa in the collection was calculated as:

$$
\mathrm{H}^{1}
$$

$$
\mathrm{E}=\overline{\mathrm{H} \max }
$$

Where:

$\mathrm{H}^{1}=$ Shannon weiner index diversity

$\mathrm{H} \max =$ maximum expected diversity $=\log \mathrm{K}$

- Species richness or variety index (d) was calculated as:

$$
\mathrm{d}=\frac{\mathrm{S}-1}{\log \mathrm{N}}
$$

Where:

$\mathrm{S}=$ No. of species

$\mathrm{N}=\mathrm{No}$ of individuals in a species (Brockway and Lewis 1997) 


\section{Statistical analysis of data}

Ecological parameters viz; diversity, evenness and richness were subjected to analysis of variance using SAS statistical package based on randomized complete block design (Steel and Torrie, 1980). Means that were significantly different were separated by LSD.

\section{RESULTS}

\section{Plant species diversity}

As shown by Shannon Weiner diversity index, the diversity of the shrub species was higher $(\mathrm{p}<0.05)$ in the early burnt plot $\left(\mathrm{H}^{1}=0.86\right)$ than in the late burnt plot $\left(\mathrm{H}^{1}=0.66\right)$ even though the species richness index in the late burnt plot $(\mathrm{d}=3.31)$ was higher than that of the early burnt plot $(\mathrm{d}=2.50)$ (Table 1$)$. Furthermore, species evenness index was higher $(\mathrm{p}<0.05)$ in the early burnt plot $(E=1.00)$ than in the late burnt plot $(E=0.92)$, indicating that the shrub species in the early burnt plot showed greater uniformity in the distribution of individuals among the taxa hence the higher species diversity. Similarly for forbs and grasses, the diversity index was highest in the early burnt plot $\left(\mathrm{H}^{1}=0.89\right)$ while it was least in the late burnt plot $\left(\mathrm{H}^{1}=0.83\right)$.
The species evenness was higher in early burnt plot than in the late burnt plot (Table 2).

\section{Forbs and grass biomass}

The grass and forbs species biomass production were higher in the early burnt plot than in the late burnt plot during the ninemonth post fire sampling period. Although the grass biomass production was initially higher in the fire protected plot (Table 3), this trend was reversed at the sixth month after burning when the grass biomass production in the early burnt plots became consistently higher than even the fire protected plots throughout the remaining sampling period. The grass biomass in the late burnt plot remained perpetually lowest throughout the nine-month sampling period (Table 3). Similarly the forbs biomass production was perpetually higher in the early burnt than in the fire protected plot at five month after burning while the forbs biomass production in the late burnt plot remained perpetually the lowest throughout the nine-month period (Table 4). However burning initiated higher forbs biomass than the biomass of grasses (Table 3 and 4) throughout the nine- month post fire sampling period.

Table 1: Diversity, evenness and richness indices of shrubs species in Dabagi forest reserve as affected by burning regimes.

\begin{tabular}{lccc}
\hline \multicolumn{3}{c}{ Burning regime } \\
\hline Ecological indices & Fire protected & Early burn & Late burn \\
Diversity index (H) & $0.89^{\mathrm{a}}$ & $0.86^{\mathrm{a}}$ & $0.66^{\mathrm{b}}$ \\
Evenness index (E) & $0.99^{\mathrm{a}}$ & $1.00^{\mathrm{a}}$ & $0.92^{\mathrm{b}}$ \\
Richness index (d) & $2.52^{\mathrm{a}}$ & $2.50^{\mathrm{a}}$ & $3.31^{\mathrm{b}}$ \\
\hline Means followed by the same superscript in a row are not significantly different $(\mathrm{p}>0.05)$.
\end{tabular}

Table 2: Diversity, evenness and richness indices of forb and grass species in Dabagi forest reserve as affected by burning regimes.

\begin{tabular}{lccc}
\hline \multicolumn{3}{c}{ Burning regime } \\
\hline Ecological indices & Fire protected & Early burning & Late burning \\
\hline Diversity index (H) & $0.84^{\mathrm{a}}$ & $0.89^{\mathrm{b}}$ & $0.83^{\mathrm{a}}$ \\
Evenness index (E) & $0.93^{\mathrm{a}}$ & $0.97^{\mathrm{b}}$ & $0.92^{\mathrm{a}}$ \\
Richness index (d) & $2.43^{\mathrm{a}}$ & $0 . .97^{\mathrm{b}}$ & $0.93^{\mathrm{a}}$ \\
\hline Means followed by the same superscript in a row are not significantly different $(\mathrm{p}>0.05)$.
\end{tabular}


Table 3: Biomass of grasses as influenced by burning regime during nine-month post burning period in Dabagi Forest Reserve.

\begin{tabular}{lccc}
\hline $\begin{array}{l}\text { Post burning } \\
\text { Sampling period }\end{array}$ & \multicolumn{3}{c}{ Grass biomass $\left(\mathbf{g} / \mathbf{m}^{2}\right)$} \\
\hline Month & Fire protected & Early burn & Late burn \\
\hline 1 & 55 & 46 & 12 \\
2 & 75 & 52 & 25 \\
3 & 90 & 58 & 30 \\
4 & 115 & 60 & 45 \\
5 & 125 & 65 & 53 \\
6 & 135 & 145 & 60 \\
7 & 142 & 156 & 71 \\
8 & 155 & 175 & 79 \\
9 & 158 & 210 & 85 \\
\hline
\end{tabular}

Table 4: Biomass of forbs as influenced by burning regime during nine-month post burning period in Dabagi Forest Reserve.

\section{Post burning \\ Sampling period \\ Biomass of forbs $\left(\mathrm{g} / \mathrm{m}^{2}\right)$}

\begin{tabular}{lccc}
\hline Month & Fire protected & Early burn & Late burn \\
\hline 1 & 90 & 65 & 20 \\
2 & 95 & 70 & 31 \\
3 & 103 & 85 & 52 \\
4 & 152 & 90 & 75 \\
5 & 155 & 165 & 125 \\
6 & 160 & 178 & 138 \\
7 & 162 & 195 & 145 \\
8 & 165 & 235 & 152 \\
9 & 170 & 248 & 158 \\
\hline
\end{tabular}




\section{DISCUSSION}

\section{Plant species diversity}

The Shannon weiner species index $\left(\mathrm{H}^{1}\right)$ describes how variable the species are, while the species richness index refers to the number of species that occurred in a defined area. Species evenness index (E) expresses the degree of uniformity in the distribution of species among the taxa. The result of this study consistently indicated a higher species evenness and diversity in the early burnt plot than in the late burnt and the fire protected plots. This observation agrees with report from previous studies (Archer et al., 1988; Brockway and Lewis, 1997). As reported by Collins (2000), late or dry season burning reduce plant species diversity by promoting the dominance of a limited number of dry season species while the wet season or early burning tend to increase community diversity by promoting regeneration and growth of larger number of late flowering shrubs and forbs. Thus, as observed from the result of this study, the late season burnt plot although increase the species richness, the species are less even than in the early burnt plot, hence a lower species diversity. The result of this study also corroborate earlier report by Archer et al. (1988) and Tillman and Downing (1994) who in their independent studies on the taxonomic, spatial and structural component of the grass land ecosystems concluded that fire can potentially increase or decrease plant species diversity at landscape scales. Hence an ideal fire regime requires the development of a range of wildland fire research.

\section{Plant biomass production}

The biomass production of grasses and forbs were stimulated by both early and late burning and they both exceeded the production in the fire protected plot at five and six months after burning for the forbs and grass respectively. However, the forbs and grass biomass production in the early burnt plot remained perpetually higher than in the late burnt and fire protected plot. These findings corroborate the earlier report by Sanford (1980) who noted that primary production of the herbaceous and woody plant species are generally higher with early (light) burning than with late burning. The observed higher biomass production of both grass and forbs species in the burnt plots in excess of the fire protected plot could be attributed to an increase in growth resources such as light and soil nutrient after fire which favours seedling recruitment and establishment. Besides, changes in temperature during burning could have important repercussions for post fire plant development. For instance, elevated temperature could heighten the activities of soil microbes, thus further enhancing decomposition and nutrient release from the sites. The nutrient released may therefore facilitate post fire plant growth. It is therefore not surprising that higher grass and forbs species biomass production occurred at some stage after burning in the early burnt plot than in the late or fire protected plots. This was because early burning favours higher composition of elemental plant nutrient and provides more favourable conditions for their further release. Furthermore, as noted earlier (Russel et al., 2000), the germination of many seeds is often stimulated by fire which hitherto functioned as a pre-germination treatment of such seeds.

\section{Conclusion}

Plant species diversity indices and plant biomass production are all favoured by early burning than late burning. Therefore, for fire to be a good management tool in sustaining grassland ecosystem burning should be carried out around November (early burn) and this regime should be sustained and protected.

\section{REFERENCES}

Agee JK. 1993. Fire Ecology of Pacific Northwest Forests (vol. 4). Island Press: Washington DC; 93.

Archer S, Scrifres CJ, Bassham CR, Mangion R. 1988. Autogenic succession in a Subtropical Savanna. Conversion of grassland to thorn woodland. Ecol. Monogr., 58: 111-127.

Brockway DG, Lewis CE. 1997. Long-term effects of dormant-session prescribed fire on plant community diversity, structure and productivity in a long leaf pine wire grass ecosystem. For. Ecol. Manage., 96: 167-183.

Collins SL. 2000. Fire frequency and community heterogeneity in Tallgrass prairie. Vegetat Ecol., 73: 201-206.

Dyke FV, Sara E, Christy VK, Page E, Van Beck JG. 2004. Restoration efforts for 
plant and bird community in Tall grass prairies using prescribed burning and mowing. Restorat. Ecol., 12: 575-585.

Federal Surveys. 1964. Topographic map sheet 29NW Dange. Federal Ministry of Surveys, Lagos, Nigeria.

Johnson CG, Clausnitzer RR, Mehringer PJ, Oliver CD. 1994. Biotic and abiotic processes of eastside ecosystems: The effects of management on plant and community ecology and on stand and landscape vegetation dynamics. U.S. Forest Service general Technical Report PNW-GTR-322, 66 p.

Martin RE, Sapsis DB. 1992. Fires as Agents of Biodiversity: Pyrodiversity Promotes Biodiversity. In Technical Coordinators. Harris RR, Erman DC (eds). Proceedings of the Symposium on Biodiversity of Northwestern California. Report 29, Wildland Resources Center, University of California: Berkeley; 150-157.
Oliver CD, Larson BC. 1990. Forest Stands Dynamics. Mcgraw-Hill: New York; 467.

Romme WH, Despain DG. 1989. Historical perspective on the Yellowstone fires of 1988. Bioscience, 39: 695-699.

Russel SS, Tony, Wainarski J. 2000. Savanna Burning. Understanding and using fire in N. Australia. Tropical Savanna, CRC: Darwin.

Sanford WW. 1980. Savanna: A general review: Paper delivered at the MAB state-of-knowledge Workshop on Nigerian Savanna. April 1980, New Bussa.

Steel RGD, Torrie JH. 1980. Principles and Procedures of Statistics. McGraw Hill Book Coy, Inc: New York, USA.

Tillman D, Downing JT. 1994. The ecological consequences of changes in biodiversity: A search for General principles. Ecology, 80: $1455-1474$. 